DOI: 10.12737/article_5c1a3235d34735.47391674

УДК 633.63:631.531.1

СПОСОБЫ ПРЕДПОСЕВНОЙ ПОДГОТОВКИ СЕМЯН И МЕТОДИКА ИХ МОДЕЛИРОВАНИЯ

кандидат технических наук И. И. Бартенев ${ }^{1}$

доктор сельскохозяйственных наук О. А. Подвигина ${ }^{1}$

кандидат сельскохозяйственных наук Д. С. Гаврин ${ }^{1}$

И. В. Подосинников ${ }^{2}$

1 - ФГБНУ «Всероссийский НИИ сахарной свеклы и сахара им. А.Л. Мазлумова», пос. ВНИИСС, Российская Федерация

2 - ООО «Ольховатский семенной завод», п. Ольховатка, Воронежская область, Российская Федерация

В связи с совершенствованием технологий возделывания различных культур изменяются и способы предпосевной подготовки семян. Наиболее перспективными в настоящее время являются способы дражирования, минидражирования и инкрустации. Рассмотрены основные этапы развития способов предпосевной подготовки семян, отмечены их особенности и факторы, влияющие на прорастание семян: толщина оболочки драже и его состав, почвенные и погодные условия в период сева. Для определения математической модели влияния вышеуказанных факторов на прорастание семян была использована теория планирования эксперимента. Выбор лучших вариантов опыта осуществлялся с позиции обобщенного критерия оптимальности и функции желательности ранее используемых при оптимизации процессов деревообработки. Объектом исследований являлись семена гибрида сахарной свеклы отечественной селекции Каскад. Для оценки качества предпосевной подготовки были выбраны показатели энергии прорастания и лабораторной всхожести семян. Полевые и лабораторные опыты проведены в 2016-2017 гг. отделом семеноводства и семеноведения ФГБНУ «ВНИИСС им. А.Л. Мазлумова». При проведении лабораторных исследований в качестве варьируемых параметров были выбраны влажность почвы от 12 до $24 \%$, толщина оболочки драже до 1.0 мм, концентрация связующего вещества - от 6.0 до 10.0 л/т. Для моделирования предпосевной подготовки семян способами дражирования, минидражирования и инкрустации свеклосемена шлифовались со снятием околоплодника на 10-20 \%, 20-30 \% и 30-40 \%. Результаты экспериментальных исследований в натуральных значениях и в соответствии с используемой функцией желательности показали, что при наименьшей влажности почвы лучшие результаты имели инкрустированные и минидражированные семена. На основе экспериментальных данных рассчитана математическая модель процесса прорастания семян при различных способах предпосевной подготовки семян и влажности почвы в виде уравнений регрессии второго порядка. Анализ коэффициентов регрессии позволил установить значимость исследуемых факторов и их взаимосвязь.

Ключевые слова: сахарная свекла, свеклосемена, функция желательности, предпосевная подготовка, дражирование, минидражирование, инкрустация.

\title{
METHODS OF PRE-SEEDING PREPARATION OF SEEDS AND METHOD OF THEIR SIMULATION $\mathrm{PhD}$ (Engineering) I. I. Bartenev ${ }^{1}$ \\ DSc (Agriculture) O. A. Podvigina ${ }^{1}$ PhD (Agriculture) D. S. Gavrin ${ }^{1}$ \\ I. V. Podosinnikov ${ }^{2}$ \\ 1 - Federal State Budgetary Scientific Institution «All-Russian Research Institute of Sugar Beet and Sugar named after A.L. Mazlumov»», village VNIISS, Russian Federation \\ 2 - Olkhovatsky Seed Plant LLC, Olkhovatka, Voronezh Region, Russian Federation
}

\begin{abstract}
In connection with the improvement of the technology of cultivation of various crops, the methods of pre-sowing seed preparation are also changing. The most promising at the present time are the methods of coating, minidragulation and grafting.
\end{abstract}


The main stages of development of pre-plant seed preparation methods are considered; their features and factors affecting seed germination (shell layer and its composition, soil and weather conditions during the sowing period) are noted. To determine the mathematical model of the influence of the above factors on seed germination, the theory of experiment planning has been used. The choice of the best experience options has been carried out from the perspective of a generalized optimality criterion and desirability function previously used in the optimization of wood processing processes. The object of research was seeds of sugar beet hybrid of domestic selection Cascade. To assess the quality of pre-sowing preparation, the parameters of germination energy and laboratory germination of seeds have been selected. Field and laboratory experiments have been conducted in 2016-2017 by All-Russian Research Institute of Sugar Beet and Sugar named after A.L. Mazlumov. When conducting laboratory studies, soil moisture content was from 12 to $24 \%$, the drage shell thickness was up to $1.0 \mathrm{~mm}$, and the concentration of binder was 6.0 to $10.0 \mathrm{l} / \mathrm{t}$ as variable parameters. To simulate the pre-sowing preparation of seeds by the methods of coating, minidragulation and grafting of beet seeds, they were ground with the removal of the pericarp by $10-20 \%, 20-30 \%$ and $30-40 \%$. The results of experimental studies (in natural values and in accordance with the used function of desirability) have showed that grafted and minidradged seeds had the best results with the lowest soil moisture. On the basis of experimental data, a mathematical model of the process of seed germination has been calculated for various methods of pre-sowing seed preparation and soil moisture in the form of second-order regression equations. The analysis of the regression coefficients allowed establishing the significance of the studied factors and their relationship.

Keywords: sugar beet, beet seed, function of desirability, pre-sowing preparation, coating, minidragulation, grafting.

В настоящее время используются следующие наиболее эффективные способы предпосевной подготовки семян: дражирование, минидражирование (капсулирование, пралинаж) и инкрустирование. Эти приемы позволяют получить более точное распределение семян при посеве различными типами сеялок, а также обеспечить растения в начальный период вегетации сбалансированным минеральным питанием и создать надежную защиту проростков от вредителей и болезней.

Дражирование как одна из форм обработки семян сахарной свеклы распространилось в Европе после 1965 года. До этого времени опыты с дражированными семенами давали отрицательные результаты. Так, например, в ЧССР дражированные семена при испытаниях снижали всхожесть семян до 50 \% [9]. Однако уже в 1975 году в результате пятилетних опытов было получено снижение полевой всхожести у дражированных семян всего на 1-5 \% [10]. Исследования показали, что при росте толщины оболочки драже энергия прорастания семян несколько снижалась, полевая всхожесть, напротив, повышалась с ростом величины дражировочного слоя до некоторого оптимума и имела максимальное значение при толщине оболочки 0,75-1,5 мм. Было также установлено, что скорость прорастания дражированных семян находится в тесной взаимосвязи с количеством влаги и доступом воздуха к собственно семени. При этом отмечено, что дражированные семена имели в большинстве случаев более узкий диапазон экологических условий для прорастания, чем недражированные [11, 12].

Переворот в технологии предпосевной подготовки совершило открытие эффективных компонентов для состава дражировочной массы - инертных наполнителей и связующих веществ, наносимых на семена в малых дозах. В качестве наполнителей стали применяться новые влагоаккумулирующие вещества, позволяющие уменьшить толщину слоя дражировочной массы (капсулирование или пралинаж) и одновременно повысить прочностные характеристики оболочки. Использование таких материалов позволило наносить достаточное количество защитных и питательных препаратов на каждое отдельно взятое семя (при условии равномерности обработки) при различных способах предпосевной подготовки, в том числе и при инкрустации.

Инкрустация семян наряду с дражированием представляет в настоящее время сложный технологический процесс. При инкрустации на семена последовательно наносится несколько слоев в виде пленок, содержащих различные препараты. Такие семена не «пылят» в процессе посева и предназначены в основном для условий неустойчивого увлажнения. Так, например, доля инкрустированных семян гибридов са- 


\section{Технологии. Машины и оборудование}

харной свеклы, выпускаемых компанией КВС, составляет 8-10 \% от общего количества посевного материала.

Практический опыт, полученный при предпосевной подготовке семян и посеве различных культур в полевых условиях, показал, что различные виды подготовки семян неодинаково влияют на их посевные характеристики. Поэтому при разработке новых композиций материалов и препаратов, используемых для дражирования, минидражирования и инкрустации, требуется учитывать следующие факторы:

- влияние толщины оболочки драже на посевные качества семян;

- влияние пленкообразующих препаратов на посевные качества семян;

- влияние влажности почвы на прорастание семян, подготовленных различными способами;

- определение влияния совокупности данных факторов на посевные качества семян.

В качестве объекта исследований для оптимизации вида предпосевной подготовки использовались семена диплоидного гибрида сахарной свеклы отечественной селекции Каскад. Основой для наполнителя драже была выбрана древесная мука, используемая как в отечественном (ООО «Ольховатский семзавод»), так и в зарубежном производстве дражированных семян. В качестве связующего вещества использовались декстрин и альгинат натрия.

Одним из важнейших факторов, влияющих на прорастание семян в полевых условиях, является влажность почвы. Из литературных источников известно, что лучшие условия для роста и развития растений сахарной свеклы создаются при влажности почвы 70-80 \% от полной полевой влагоемкости, что соответствует приблизительно 22-28 \% влаги к абсолютно сухой почве [1]. При таких показателях влажности почва достигает физической спелости - не мажется и хорошо крошится, количества влаги достаточно для набухания и прорастания семян. При более высокой степени влажности ухудшается аэрация почвы и происходит снижение качества работы сеялок и культиваторов из-за залипания рабочих органов почвой [8]. Однако при значениях 40-60 \% влажности от полной полевой влагоемкости, при условии отсутствия высоких температур, суховеев и соблюдения агротехнических требований при посеве, семена сахарной свеклы могут успешно аккумулировать влагу и прорастать. Поэтому при проведении лабораторных исследований с использованием для проращивания кварцевого песка (по ГОСТ 22617.2 - 94) нами были выбраны следующие значения влажности почвы и ее абсолютно сухой массы: $16 \%, 20 \%$ и $24 \%$ [5]. Это примерно соответствует $60 \%, 70 \%$ и 80 \% влажности почвы от ее полной влагоемкости.

Для определения влияния вышеуказанных факторов на прорастание свеклосемян и выбора способа их предпосевной подготовки была использована теория планирования эксперимента. Выбор лучших вариантов опыта осуществлялся с позиции обобщенного критерия оптимальности и функции желательности, ранее используемых при оптимизации процессов деревообработки и в сельском хозяйстве для посадки корнеплодов $[2,3,4]$.

Для оценки качества предпосевной подготовки семян были выбраны два критерия. Первый $\left(m_{l}\right)$ являлся показателем энергии прорастания, второй $\left(m_{2}\right)$ определялся показателем лабораторной всхожести семян сахарной свеклы. Фракционный состав калиброванных семян гибрида Каскад - 3,5-4,5 мм, энергия прорастания (ЭП) исходного образца семян составляла 91 \%, а лабораторная всхожесть (ЛВ) - 95 \%. На каждый из критериев были наложены ограничения путем задания функции желательности.

Исходя из теории функции желательности, критерии качества изменяются от 0 до 1 , а сама функция желательности имеет вид

$$
m_{i}=e^{-e^{-\left(b_{o i}+b_{1 i} * \Delta \Pi_{i}\right)}}
$$

где $b_{o i} ; b_{l i}$ - расчетные коэффициенты;

$e$ - натуральный логарифм;

$\Delta \Pi_{i}-$ процент снижения посевных показателей семян ниже допустимой нормы.

$$
\Delta \Pi_{1}=m_{1 \text { исх }}-m_{1 \text { экс }},
$$

где $m_{1 и C X}-$ показатель ЭП исходного образца семян $(\%)$

$m_{\text {ІэкС }}-$ показатель ЭП семян после предпосевной подготовки (\%).

$$
\Delta \Pi_{2}=m_{2 \text { исх }}-m_{2 э к с}
$$

где $m_{2 и С X}-$ показатель ЛВ исходного образца семян $(\%)$

$m_{2 э к C}-$ показатель ЛВ семян после предпосевной подготовки (\%).

Коэффициенты $b_{o i}$ и $b_{l i}$ определяются в результате решения системы уравнений 


$$
\begin{aligned}
& b_{o i}+b_{0 i} * \Delta \Pi_{i \min }=\ln \ln \left(1 / m_{i}^{\prime}\right), \\
& b_{o i}+b_{0 i} * \Delta \Pi_{i \max }=\ln \ln \left(1 / m_{i}^{\prime \prime}\right),
\end{aligned}
$$

где $\Delta \Pi_{i}$ min и $\Delta \Pi_{i} \max$ - минимально и максимально допустимое снижение соответствующих показателей.

Для критерия $m_{l}$ принимаем минимально допустимым снижением величину от 0 до $4 \%$, а максимально допустимым - от 4 до $9 \%$. Для критерия $m_{2}$ минимально допустимым снижением лабораторной всхожести принимаем от 0 до $3 \%$, максимальным для исходной партии семян - от 3 до $7 \%$, что составляет у данной партии семян 88 \% лабораторной всхожести и допускается ГОСТ 32066-2013 [7].

Для использования функции желательности принимаем $m_{i}^{\prime}=0,2 ; m_{i}=0,8$. Выбор оптимальных режимов предпосевной подготовки семян осуществлялся с позиции максимально обобщенного критерия качества

$$
m_{0}=m_{1} m_{2} \rightarrow \max .
$$

Подставляя допустимые ограничения в выражения (4) и (5) и преобразуя их, получаем следующие системы уравнений:

$$
\begin{aligned}
& \left\{\begin{array}{c}
b_{01}+b_{11} 4=-\ln \ln (1 / 0.8)=1.5 \\
b_{01}+b_{11} 9=-\ln \ln (1 / 0.2)=-0.476
\end{array}\right. \\
& \left\{\begin{array}{c}
b_{02}+b_{12} 3=-\ln \ln (1 / 0.8)=1.5 \\
b_{02}+b_{12} 7=-\ln \ln (1 / 0.2)=-0.476
\end{array}\right. \\
& \text { откуда } b_{01}=3,080 ; b_{11}=-0,395 \\
& b_{02}=2,982 ; b_{12}=-0,494
\end{aligned}
$$

Исходя из этого, искомые функции желательности запишутся в следующем виде:

$$
\begin{aligned}
& m_{1}=\exp \left[-\exp \left(-3.080+0.395 \Delta \Pi_{1}\right)\right] \\
& m_{2}=\exp \left[-\exp \left(-2,982+0.494 \Delta \Pi_{2}\right)\right]
\end{aligned}
$$

Предварительно для каждого критерия были заданы уровни желательности и проводилась их оценка, основанная на предъявляемых требованиях и свойствах изучаемого объекта (табл. 1, 2).

Для оценки качества предпосевной подготовки семян нами были определены варьируемые параметры выбранных модифициру-ющих факторов (табл. 3). А для построения математической модели в указанном виде был выбран $b$-план второго порядка, дополненный для большей достоверности опытом в центре плана (табл. 4).

\begin{tabular}{|c|c|c|c|c|c|c|}
\hline \multirow[b]{2}{*}{ Факторы } & \multicolumn{2}{|c|}{ Обозначение } & \multirow{2}{*}{$\begin{array}{c}\text { Интервал } \\
\text { варьирования }\end{array}$} & \multicolumn{3}{|c|}{ Уровни варьирования } \\
\hline & натуральное & нормализованное & & $\begin{array}{c}\text { нижний } \\
(-1)\end{array}$ & $\begin{array}{c}\text { основной } \\
(0)\end{array}$ & $\begin{array}{c}\text { верхний } \\
(+1)\end{array}$ \\
\hline 1. Влажность почвы, \% & $W$ & $X_{1}$ & 6,0 & 12,0 & 18,0 & 24,0 \\
\hline 2. Толщина слоя драже, мм & $h$ & $X_{2}$ & 0,5 & 0,0 & 0,5 & 1,0 \\
\hline 3. Концентрация связующего, л/т & $k$ & $X_{3}$ & 2,0 & 6,0 & 8,0 & 10,0 \\
\hline
\end{tabular}

Таблица 1

Оценка критерия «энергия прорастания»

\begin{tabular}{|c|c|c|}
\hline Качественная оценка & Диапазон изменения $m_{l}$ & Величина $\Delta \Pi_{i}$ \\
\hline Хорошо & $0,80-1,00$ & $6-0$ \\
\hline Удовлетворительно & $0,63-0,80$ & $9-7$ \\
\hline Неудовлетворительно & $0,37-0,63$ & более 9 \\
\hline Плохо & $0,00-0,37$ & \\
\hline
\end{tabular}

Таблица 2

Оценка критерия «лабораторная всхожесть»

\begin{tabular}{|c|c|c|}
\hline Качественная оценка & Диапазон изменения $m_{2}$ & Величина $\Delta \Pi_{2}$ \\
\hline Хорошо & $0,80-1,00$ & $4-0$ \\
\hline Удовлетворительно & $0,63-0,80$ & $7-6$ \\
\hline Неудовлетворительно & $0,37-0,63$ & более 7 \\
\hline Плохо & $0,00-0,37$ & \\
\hline
\end{tabular}

Таблица 3

Варьируемые параметры факторов 
План эксперимента

\begin{tabular}{|c|c|c|c|c|c|}
\hline № п/п & $X_{I}$ & $X_{2}$ & $X_{3}$ & Порядковый номер опыта & Применение \\
\hline 1. & +1 & +1 & +1 & 13 & \multirow{8}{*}{ Опыт ПФП } \\
\hline 2. & +1 & +1 & -1 & 2 & \\
\hline 3. & +1 & -1 & +1 & 8 & \\
\hline 4. & +1 & -1 & -1 & 15 & \\
\hline 5. & -1 & +1 & +1 & 1 & \\
\hline 6. & -1 & +1 & -1 & 6 & \\
\hline 7. & -1 & -1 & +1 & 11 & \\
\hline 8. & -1 & -1 & -1 & 4 & \\
\hline 9. & +1 & 0 & 0 & 7 & \multirow{6}{*}{ Звездные точки } \\
\hline 10. & -1 & 0 & 0 & 5 & \\
\hline 11. & 0 & +1 & 0 & 9 & \\
\hline 12. & 0 & -1 & 0 & 3 & \\
\hline 13. & 0 & 0 & +1 & 10 & \\
\hline 14. & 0 & 0 & -1 & 12 & \\
\hline 15. & 0 & 0 & 0 & 14 & Опыт в центре план \\
\hline
\end{tabular}

Зависимость критериев оптимальности от варьируемых параметров определялась регрес-сивной моделью второго порядка с учетом парных взаимодействий. Для уменьшения систематической ошибки последовательность проведения запланиро-ванных опытов рандомизировалась по времени. Номера опытов были заданы на основании теории случайных чисел. В этом варианте ошибка при определении коэффициентов регрессии не превысила $3 \Delta n / 4$, где $\Delta n$ - увеличение систематической ошибки в каждом запланирован-ном опыте.

Для определения оптимального сочетания факторов $X_{1}, X_{2}$ и $X_{3}$ необходимо для выбранных диапазонов варьирования получить математическое описание поверхности отклика. Наиболее подходящим для проведения данных исследований является центральный композиционный ротатабельный план, позволяющий получить равномерную информацию по всем направлениям факторного пространства.

Для математического моделирования процесса предпосевной подготовки нами были проведены экспериментальные исследования. Предпосевная подготовка семян заключалась в их шлифовании, последующем инкрустировании, минидражировании и дражировании. Шлифование осуществляли последовательно в три этапа: на $10-20 \%, 20-30 \%$ и 30-40 \% снятия околоплодника семян. В результате проведенной операции на лабораторных решетах были отобраны семена следующих фракций: более 3,5 мм - для инкрустации, 3,0-3,5 - для минидражирования, менее 3,0 для дражирования. Последующее накатывание на семена дражировочной массы совместно со связующим веществом осуществляли на лабораторном дражираторе и установке для инкрустации «Hege 11».

При проведении инкрустации связующее вещество наносилось в два приема. Первый слой моделировал нанесение на семена ростостимули-рующих препаратов и фунгицидов. Концентрация связующего в этом случае составляла 2 л/т. Второй слой моделировал нанесение на семена инсекти-цидов и фунгицидов. Концентрация связующего в этом случае, в соответствии с вариантами опыта, составляла 4 л/т, 6 л/т и 8 л/т. Общая схема обработки пленкообразующим препаратом семян имела следующий вид: $2+4$ л/т, $2+6$ л/т, $2+8$ л/т.

При определении посевных характеристик семян, подготовленных различными способами, использовали в качестве ложа кварцевый песок. Песок подготавливался к посеву по ГОСТ 22617.2 - 94 и увлажнялся в соответствии со схемой опыта (рис. 1).

Определение влагоемкости песка показало, что увлажнение до $24 \%$ соответствует $80 \%$ от полной влагоемкости, увлажнение песка до $20 \%$ соответствует $60 \%$ от полной влагоемкости, а увлажнение до $16 \%$ соответствует приблизительно $40 \%$ от полной влагоемкости данной партии песка. Энергию прорастания 


\section{Технологии. Машины и оборудование}

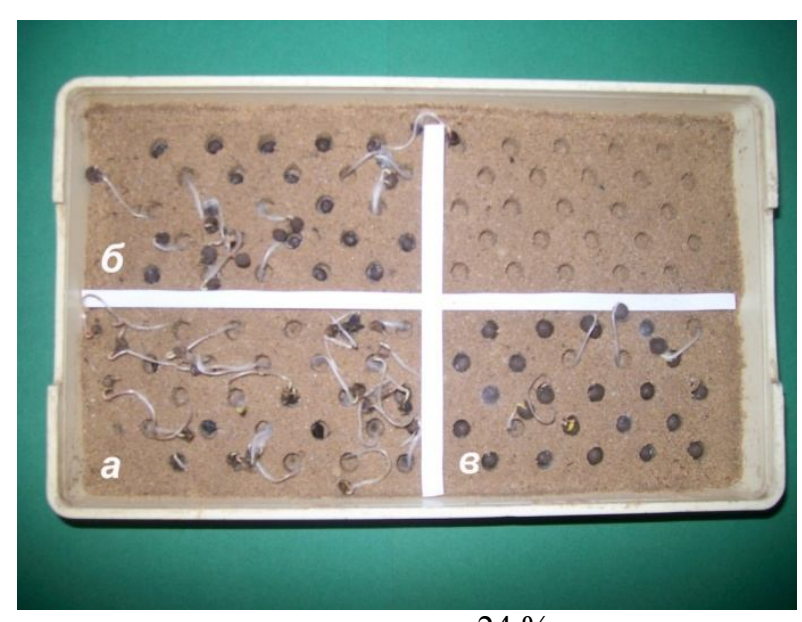

увлажнение до $24 \%$

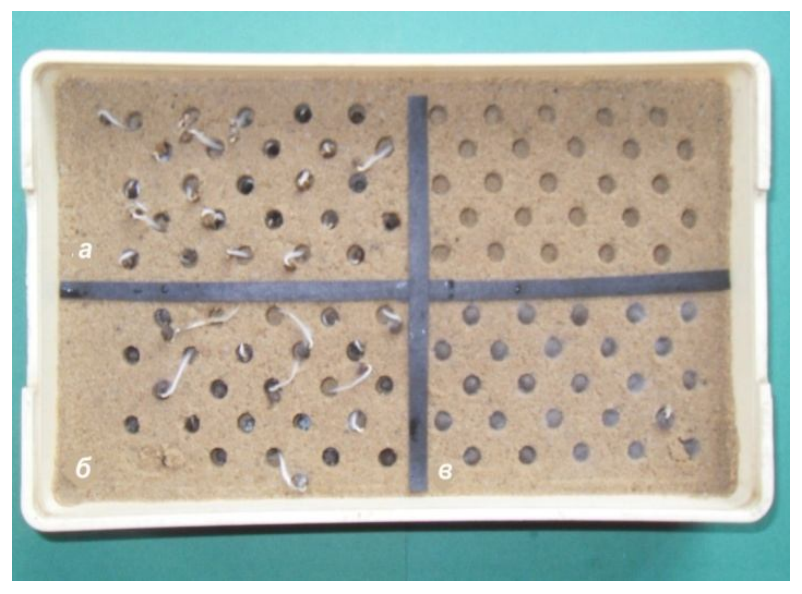

увлажнение до $16 \%$

Рис. 1. Прорастание семян при различной степени влажности песка

а) инкрустированные; б) минидражированные;

в) дражированные семян определяли на четвертый день, а лабораторную всхожесть - на десятый день от посева. Результаты экспериментальных исследований представлены в натуральных значениях в соответствии с используемой функцией желательности (табл. 5).

Анализ показал, что условиям недостаточного увлажнения соответствуют варианты 5-8 и 10. Из этих вариантов, исходя из обобщенного критерия оптимальности, лучшими можно считать варианты 8 и 10. В соответствии с этими вариантами опытов лучшие показатели имели инкрустированные и минидражированные семена. Так, у инкрустированных семян при их проращивании в условиях меньшей влажности $(w=12 \%)$ снижение энергии прорастания произошло на 4,0 \%, лабораторной всхожести - на 3,9 \%. У минидражированных семян снижение данных показателей составило 4,9 \% и 2,0 \% соответственно. У дражированных семян лучший показатель в этих условиях составил: снижение энергии прорастания на 8,1 \%, снижение лабораторной всхожести на 4,5 \%. Худшие показатели у дражированных семян были при минимальной влажности и максимальной концентрации связующего вещества. В этом случае энергия прорастания снизилась на 12,7 \%, а лабораторная всхожесть на $9,0 \%$.

На основе полученных экспериментальных данных нами была рассчитана математическая модель процесса прорастания семян при различных способах предпосевной подготовки и влажности почвы в виде

Таблица 5

Результаты экспериментальных исследований

\begin{tabular}{|c|c|c|c|c|c|}
\hline № $\Pi / \Pi$ & $\Pi_{I}, \%$ & $m_{l}$ & $\Pi_{2}, \%$ & $m_{2}$ & $m_{0}$ \\
\hline 1 & 7,2 & 0,48 & 4,1 & 0,70 & 0,34 \\
\hline 2 & 3,5 & 0,86 & 4,0 & 0,70 & 0,60 \\
\hline 3 & 5,6 & 0,63 & 3,8 & 0,70 & 0,44 \\
\hline 4 & 2,0 & 0,91 & 2,3 & 0,87 & 0,79 \\
\hline $\mathbf{5}$ & $\mathbf{1 2 , 4}$ & $\mathbf{0 , 0 0}$ & $\mathbf{9 , 0}$ & $\mathbf{0 , 3 1}$ & $\mathbf{0 , 0 0}$ \\
\hline $\mathbf{6}$ & $\mathbf{8 , 1}$ & $\mathbf{0 , 3 9}$ & $\mathbf{4 , 9}$ & $\mathbf{0 , 5 5}$ & $\mathbf{0 , 2 1}$ \\
\hline $\mathbf{7}$ & $\mathbf{5 , 8}$ & $\mathbf{0 , 6 3}$ & $\mathbf{4 , 1}$ & $\mathbf{0 , 7 0}$ & $\mathbf{0 , 4 4}$ \\
\hline $\mathbf{8}$ & $\mathbf{4 , 0}$ & $\mathbf{0 , 8 0}$ & $\mathbf{3 , 9}$ & $\mathbf{0 , 8 0}$ & $\mathbf{0 , 6 4}$ \\
\hline 9 & 4,2 & 0,80 & 3,1 & 0,80 & 0,64 \\
\hline $\mathbf{1 0}$ & $\mathbf{4 , 9}$ & $\mathbf{0 , 7 2}$ & $\mathbf{2 , 0}$ & $\mathbf{0 , 8 7}$ & $\mathbf{0 , 6 2}$ \\
\hline 11 & 6,1 & 0,63 & 5,3 & 0,55 & 0,35 \\
\hline 12 & 3,6 & 0,86 & 2,5 & 0,87 & 0,75 \\
\hline 13 & 7,0 & 0,48 & 4,0 & 0,70 & 0,34 \\
\hline 14 & 5,1 & 0,72 & 3,2 & 0,80 & 0,58 \\
\hline 15 & 3,9 & 0,80 & 2,4 & 0,87 & 0,70 \\
\hline
\end{tabular}




\section{Технологии. Машины и оборудование}

уравнений регрессии второго порядка. Для нахождения коэффициентов уравнения регрессии был использован метод наименьших квадратов. Общий смысл оценивания по методу наименьших квадратов заключается в минимизации суммы квадратов отклонений наблюдаемых значений зависимой переменной от значений, предсказанных моделью. Для этого решалась следующая задача:

$$
\sum_{n-1}^{15}\left(Y_{n}-\left(b_{0}+\sum_{k i 1}^{3} b_{i} X_{n i}+\sum_{j=1}^{3} \sum_{i=1}^{3} b_{i j} X_{n i} X_{n j}\right)\right)^{2} \rightarrow \min ,
$$

где $Y_{n}, X_{n i}$ - значения параметров процесса, полученных в результате эксперимента.

В результате расчетов были получены коэффициенты уравнения регрессии. После оценки их значимости уравнения регрессии были получены в следующем виде:

$$
\begin{aligned}
m_{1}= & 0.762+0.114 x_{1}-0.147 x_{2}-0.146 x_{3}+0.105 x_{1} x_{2}-0.172 x_{3}^{2}, \\
& m_{2}=0.830-0.113 x_{2}, \\
m_{0}= & 0.612+0.09 x_{1}-0.156 x_{2}-0.126 x_{3}+0.0725 x_{1} x_{2}-0.174 x_{3}^{2},
\end{aligned}
$$

Анализ уравнений показал, что на энергию прорастания оказывают влияние как почвенноклиматические условия - влажность почвы $\left(x_{l}\right)$ - так и способы предпосевной подготовки семян - толщина слоя драже $\left(x_{2}\right)$ и концентрация связующего препарата $\left(x_{3}\right)$. На показатель всхожести наиболее сильное влияние оказывает такой фактор, как толщина слоя драже. Окончательная оценка степени влияния различных факторов и определение их оптимальных значений было проведено с помощью обобщенного критерия оптимальности $m_{0}$ (рис. 2).

Полученные графики показывают, что во всех случаях имеются ярко выраженные экстремумы функций внугри исследуемого факторного пространства. Это значит, что влияние каждого фактора на значение выходной величины непостоянно в разных точках диаграммы зависимости фактора, а с учетом парных взаимодействий определяется еще и уровнями факторов. Так, при $x_{3}=0$ максимум отклика (полученное значение) определяется влажностью почвы $\left(x_{l}\right)$ в пределах $20-24$ \% и толщиной слоя драже от 0 до 0,5 мм, соответствующей инкрусти-рованным и минидражированным семенам. При $x_{2}=0$ наилучшее значение также определяется влажностью почвы $\left(x_{I}\right)$ в пределах 20-24 $\%$ и количеством связующего вещества $\left(x_{3}\right)$ до 6 л/т.

При $x_{l}=0$ лучшие показатели имеют варианты

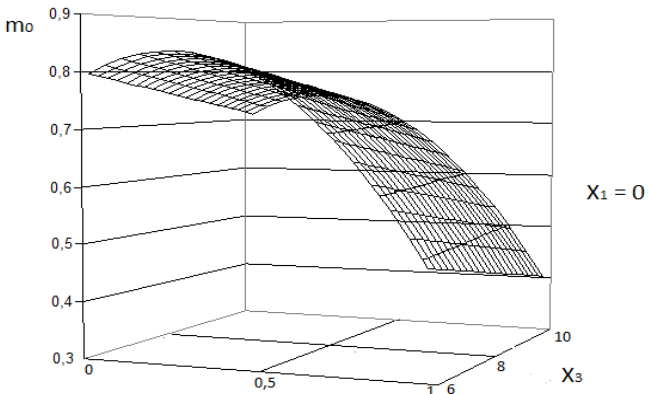

$\mathrm{X}_{2}$

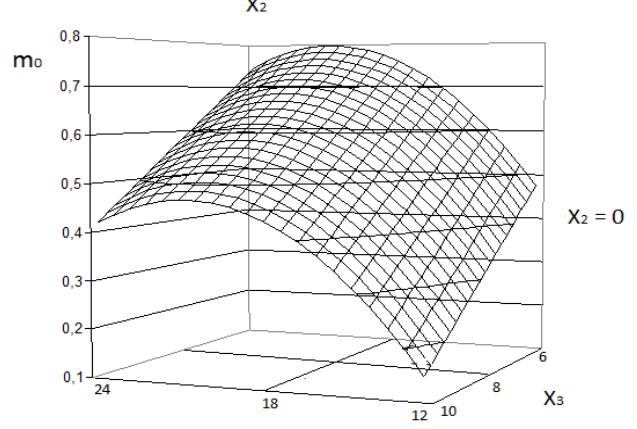

mo

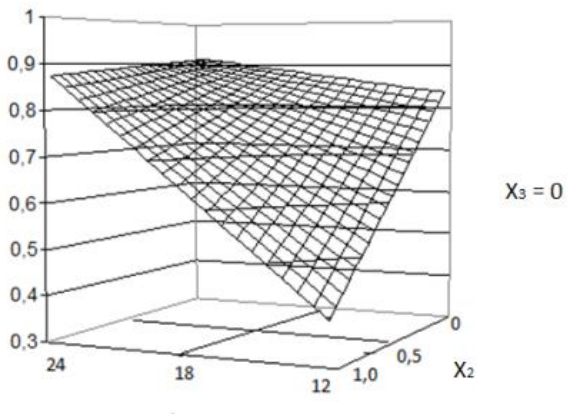

$x_{1}$

Рис. 2. Зависимость критериев оптимальности от варьируемых факторов

с толщиной слоя драже от 0 до 0,5 мм с добавлением связующего вещества из расчета 6-8 л/т. Исходя из этого, можно сделать вывод, что для влажности почвы менее $20 \%$ в зоне высева семян пред-почтительнее использовать минидражированные и инкрустированные семена.

Таким образом, предложенную методику оценки и моделирования способов предпосевной подготовки семян можно использовать для различных культур, в том числе и в лесном хозяйстве. Это позволит улучшить качество подготовки семян к посеву с учетом их биологических особенностей, посевных характеристик (энергии прорастания, лабораторной всхожести) и факторов внешней среды, складывающихся в зоне возделывания изучаемой культуры. 


\section{Библиографический список}

1. Даньков, В. Я. Сроки сева [Текст] / В. Я. Даньков // Сахарная свекла. - 1986. - № 3. - С. 40-41.

2. Евстратов, А. И. Разработка элементов влагоэнергосберегающей технологии выращивания семенников сахарной свеклы в условиях юго-восточной ЦЧЗ [Текст] : автореф. дис. ... канд. с.-х. наук: 06.01 .05 / А. И. Евстратов. - Рамонь, 2001. - 23 с.

3. Пижурин, А. А. Исследование процессов деревообработки [Текст] / А. А. Пижурин. - М. : Лесн. пром-сть, 1984. -231 с.

4. Пижурин, А. А. Основы моделирования и оптимизации процессов деревообработки [Текст] / А. А. Пижурин, М. С. Розенблит. - М. : Лесн. пром-сть, 1988. - С. 22-28.

5. Семена сахарной свеклы. Методы определения всхожести, одноростковости и доброкачественности: ГОСТ 22617.2 - 94. Введ. 1997-01-01 [Текст]. - Минск : Международный совет по стандартизации, метрологии и сертификации; М. : Изд-во стандартов, 1997. - 6 с.

6. Семена сахарной свеклы. Посевные качества. Общие технические условия: ГОСТ 32066 - 2013. Введ. 2014-07-01 [Текст]. - М. : Стандартинформ, 2014. - 12 с.

7. Синеоков, Г. Н. Теория и расчет почвообрабатывающих машин [Текст] / Г. Н. Синеоков, И. М. Панов. - М. : Машиностроение, 1977. - 305 с.

8. Fidler, J. Zpráva o zhoušach obabovaného semene cwkrovhu [Text] / J. Fidler. - Seměice, 1959.

9. Hibbert, D. Observations on the effects of different pelleting processes on the laboratory germination and field emergence of sugar beet seed [Text] / D. Hibbert, D. Thomson, W. Woodwark // J. J. R.B. - 1975. - Vol. 7. - P. $24-32$.

10. Kliêivost oba - lovaneho asiva a ehologicke fartay [Text] / K. Veverka, V. Brejeha, F. Löbl, K. Zahra-Dnir // Agrochemia. - 1979. - Vol. 19. - S. 209-213.

11. Veverka, K. Vliv pudni verosti na vzcházivost obalovaného osiva carzovky [Text] / K. Veverka // Rostl. Výe., 29, 1983, 9. - S. 937-943.

12. Wieser, F. Studie über Einflüsse verschiedener Grössen der Samenpillen auf die Keimfähigkeit und den Feldaufgang der Zuckerrübe, begozen auf das Ausgangsaatgut [Text] : Disertation / F. Wieser. - Linz, 1971.

\section{References}

1. Dankov V. Ya. Sroki seva [Seeding time]. Sugar beet, 1986, no 3. p. 40-41. (In Russian)

2. Evstratov A. I. Razrabotka elementov vlagoenergosberegayushchey tekhnologii vyrashchivaniya semennikov sakharnoy svekly $v$ usloviyakh yugo-vostochnoy TSCHZ [Development of elements of moisture-energy-saving technology of growing sugar beet tests in the conditions of the southeastern Black Soil Zone]. Ramon, 2001. 23 p. (In Russian)

3. Pizhurin A. A. Issledovaniye protsessov derevoobrabotki [Research of woodworking processes]. Moscow, 1984, 231 p. (In Russian)

4. Pizhurin A. A. Osnovy modelirovaniyya i optimizatsii protsessov derevoobrabotki [Fundamentals of modeling and optimization of woodworking processes]. Moscow, 1988, p. 22-28. (In Russian)

5. Semena sakharnoy svekly. Metody opredeleniya vskhozhesti, odnorostkovosti i dobrokachestvennosti: GOST 22617.2 - 94 [Seeds of sugar beet. Methods for determining the germination, single root and high quality: GOST 22617.2 - 94]. Minsk, Moscow, 1997, 6 p. (In Russian)

6. Semena sakharnoy svekly. Posevnyye kachestva. Obshchiye tekhnicheskiye usloviya: GOST 32066 - 2013 [Seeds of sugar beet. Sowing qualities. General technical conditions: GOST 32066 - 2013]. Moscow, 2014, 12 p. (In Russian)

7. Sineokov G. N. Teoriya i raschet pochvoobrabatyvayushchikh mashin [Theory and calculation of tillage machines]. Moscow, 1977, 305 p. (In Russian)

8. Fidler J. Zpráva o zhoušach obabovaného semene cwkrovhu. Seměice, 1959.

9. Hibbert D., Thomson D., Woodwark W. Observations on the effects of different pelleting processes on the laboratory germination and field emergence of sugar beet seed. J.J. R.B., 7, 1975, pp. 24-32.

10. Veverka K., Brejeha V., Löbl. F., Zahra-Dnir K. Kliêivost oba - lovaneho asiva a ehologicke fartay. Agrochemia, 19, 1979, pp. 209-213.

11. Veverka K. Vliv pudni verosti na vzcházivost obalovaného osiva carzovky. Rostl. Výe., 29, 1983, 9; pp. 937-943.

12. Wieser F. Studie über Einflüsse verschiedener Grössen der Samenpillen auf die Keimfähigkeit und den Feldaufgang der Zuckerrübe, begozen auf das Ausgangsaatgut : Disertation, Linz, 1971. 


\title{
Сведения об авторах
}

Бартенев Игорь Иванович - заведующий отделом семеноводства и семеноведения сахарной свеклы с элементами механизации ФГБНУ «Всероссийский научно-исследовательский институт сахарной свеклы и сахара имени А.Л. Мазлумова», кандидат технических наук, п. ВНИИСС, Воронежская область, Российская Федерация; e-mail: vniiss@mail.ru.

Подвигина Ольга Анатольевна - ведущий научный сотрудник ФГБНУ «Всероссийский научноисследовательский институт сахарной свеклы и сахара имени А.Л. Мазлумова», доктор сельскохозяйственных наук, п. ВНИИСС, Воронежская область, Российская Федерация; e-mail: vniiss@mail.ru.

Гаврин Денис Сергеевич - научный сотрудник отдела семеноводства и семеноведения сахарной свеклы с элементами механизации ФГБНУ «Всероссийский научно-исследовательский институт сахарной свеклы и сахара имени А.Л. Мазлумова», кандидат сельскохозяйственных наук, п. ВНИИСС, Воронежская область, Российская Федерация; e-mail: vniiss@mail.ru.

Подосинников Игорь Владимирович - директор ООО «Ольховатский семенной завод», п. Ольховатка, Воронежская область, Российская Федерация.

\section{Information about authors}

Bartenev Igor Ivanovich - Head of the Department of Seed Growing and Seed Research of Sugar Beets with Elements of Mechanization, FSBSI «All-Russian Research Institute of Sugar Beet and Sugar named after A.L. Mazlumov», PhD (Engineering), village VNIISS, Voronezh Region, Russian Federation; e-mail: vniiss@mail.ru.

Podvigina Olga Anatolievna - Leading Researcher, FSBSI «All-Russian Research Institute of Sugar Beet and Sugar named after A.L. Mazlumov», DSc (Agriculture), village VNIISS, Voronezh Region, Russian Federation; e-mail: vniiss@mail.ru.

Gavrin Denis Sergeevich - Researcher of the Department of Seed Growing and Seed Research of Sugar Beets with Elements of Mechanization, FSBSI «All-Russian Research Institute of Sugar Beet and Sugar named after A.L. Mazlumov», PhD (Agriculture), village VNIISS, Voronezh Region, Russian Federation; e-mail: vniiss@mail.ru.

Podosinnikov Igor Vladimirovich - director, «Olkhovatsky Seed Plant», Olkhovatka, Voronezh Region, Russian Federation.

DOI: $10.12737 /$ article_5c1a3237290288.22345283

УДК $630 * 232.318: 630 * 651.72$
АНАЛИЗ ОПЕРАЦИОННЫХ МЕХАНИЗИРОВАННЫХ ТЕХНОЛОГИЙ СЕПАРАЦИИ СЕМЯН ПРИ ИСКУССТВЕННОМ ЛЕСОВОССТАНОВЛЕНИИ
доктор технических наук, профессор М. В. Драпалюк ${ }^{1}$
кандидат технических наук, доцент А. И. Новиков ${ }^{1}$
1 - ФГБОУ ВО «Воронежский государственный университет имени Г.Ф. Морозова»,
г. Воронеж, Российская Федерация

\begin{abstract}
Выбор технологии и технических средств для сепарации семян перед посевом или хранением формируется на основании аналитической информации о применении решетной, безрешетной и оптической технологий в науке и практике искусственного лесовосстановления. Основанием для проведения исследований является необходимость нахождения четкого критерия применимости альтернативных методик сепарации лесных семян в сравнении с традиционными. В качестве методов исследования использовались структурно-функциональное моделирование и SWOT-анализ. Установлено, что применение того или иного способа механизированной сепарации семян в структуре затрат на искусственное лесовосстановление должно складываться в зависимости от вида древесной породы, назначения полученного семенного материала, экономической эффективности применения конкретного способа сепарации в определенных условиях, условий лесохозяйственного регламента, возможностей (наличия кадрового резерва, технических средств и пр.) и временного диапазона применения способа сепарации, наибольшей вероятности получения положительного результата. SWOT-анализ показывает, что основным внешним вероятным фактором, затрудняющим использование решетной
\end{abstract}

